\title{
EL POEMA CONFESIONAL
}

\author{
Rocío Oviedo PÉREZ DE TUdelA \\ Universidad Complutense de Madrid
}

\section{Resumen}

El análisis de «Yo soy aquel», primer poema de Cantos de Vida y Esperanza, refleja el cambio experimentado por Rubén Darío, especialmente en su preferencia por el simbolismo frente a la atención que presta a la forma en Prosas Profanas. Poemario más claramente hispano, con una defensa del arielismo que refleja la dedicatoria a José Enrique Rodó. Sin embargo, es en el contenido confesional del poema en el que se desvela el reino interior de Darío, marcado por la dualidad y el esfuerzo por conciliar «sus» contrarios. De la lectura atenta se observa un proceso de transformación de «la estatua bella» a «fauno» monstruoso. Fábulas como la de Eros y Psiquis sirven al poeta para expresar con mayor precisión el juego de antítesis que finaliza con «la caravana pasa», de rasgos relacionados con el gnosticismo cristiano y los rosacruces.

Palabras clave: Rubén Darío, «Yo soy aquél», arielismo, simbolismo, Eros, Psique, gnosticismo, rosacruces.

\begin{abstract}
This «Yo soy aquel» analysis —Cantos de Vida y Esperanza first poem- reflects the change experienced by Rubén Darío, especially in his preference for symbolism in the face of his attention to form in Prosas Profanas. Poemario more clearly Hispanic, with a defence of Arielism that reflects the dedication to José Enrique Rodó. However, the confessional content of the poem reveals the own kingdom of Dario signed by duality and the effort to reconcile "their" opposites. From careful reading we see a process of transformation from "beautiful statue" to "monstrous" faun. Fables like that of Eros and Psiquis serve the poet to express with more precision the play of antithesis that ends with "the caravan passes", features related to Christian Gnosticism and Rosicrucians.
\end{abstract}

Keywords: Rubén Darío, «Yo soy aquél», arielism, symbolism, Eros, Psyche, Gnosticism, Rosicrucians. 
Hasta qué punto es relevante el primer poema de Cantos, lo delata el hecho de dar título y ser el primer poema con el que, él mismo, encabeza esa otra lectura poética propuesta: una singular «Antología» que elabora para la editorial Corona: Muy siglo XVIII, al que se suman los volúmenes Muy antiguo y muy moderno y Una sed de ilusiones infinitas, versos a su vez de este primer poema de Cantos. «Yo soy aquel» se sitúa de este modo como manifiesto de manifiestos y brújula de todo su quehacer lírico, desde la reflexión de la madurez.

La crítica pone de relieve en Cantos de vida y esperanza el hispanismo de Rubén, su arielismo, y revela a su vez la transformación desde el parnasianismo presente en Prosas profanas al simbolismo que, ya en el comienzo, es el axis del poemario.

Esta circunstancia avala el propósito de iniciación poética de la obra dariana. Habitualmente el orden de los poemas no es aleatorio, sino que responde a un claro deseo de iniciación del lector, de modo que el primer poema de cada obra lírica adquiere un significado singular. Circunstancia que se puede observar desde sus primeras publicaciones.

Epistolas y poemas (1885-1888), se abre con una «Introducción» que es una salutación a la primavera, en paralelo a la juventud del autor que se identifica con ella: «En el alba de la vida/ todo es luz esplendorosa», (Darío,1952: 347). Identificación que se continúa con el reconocimiento de su condición de poeta, pero abordada desde el nosotros: «Los que traemos por don /[...]/ el ser de la inspiración» (id., 348) y la identificación entre poesía y sentimiento: «en este libro tengo / dichas que me satisfacen/ dolores que me deshacen, / ilusiones que mantengo. / Ignoro de dónde vengo / ni a dónde voy a parar». Por si aún dudábamos de que se tratase del sentimiento, finaliza con una afirmación: "pienso en Dios, pienso en mi amada /[...]/ Y después de todo, ¡siento / que hay algo en mi corazón». (id., 354).

En Abrojos, el primer poema adopta el mismo carácter introductorio, pues lo titula «Prólogo» y es un diálogo con Manuel Rodríguez Mendoza, el director de la redacción de La época, a quien brinda estos abrojos, que como indica «no hieren las manos de la amistad» (id., 496). En el poema, pese a que adquiere el tono de diario, la emoción desaparece a favor de un tono grotesco que finalmente define su propósito: « $i$ No predico, no interrogo / de un sermón, ¡qué se diría! / Esto no es una homilía /, sino amargo desahogo» (id.).

Estos poemas que se sitúan al frente de los libros varían tanto en Azul como en Prosas Profanas. En Azul, el primer escrito es un cuento, «El rey burgués» y es una afirmación del futuro que espera a la poesía y propuesta del modernismo pues el pobre poeta que muere es un romántico, herido de muerte desde el principio, aunque augure el futuro del «Nuevo sol» que vendrá, es 
decir, poetas como Rubén. Por su parte el primer poema de Prosas Profanas, «Era un aire suave», es también una afirmación de la poética, enmarcada, curiosamente, en el siglo XVIII, con la marquesa Eulalia, mujer que elige al poeta -en perfecta antítesis con el rey burgués- y cuyo misterio permanece en algo opuesto al misterio como es la risa. El mismo Darío señala que se trata de «Los caprichos siglo XVIII, mis queridas y gentiles versallerias, los madrigales galantes y preciosos y todo lo que, en su tiempo, sirvió para renovar el gusto y la forma y el vocabulario en nuestra poesía» (Darío, 1950: 214).

Finalmente, en cuanto poema confesional, el precedente inmediato a «Yo soy aquel» se encuentra en «Yo persigo una forma». Poema con el que guarda, desde el plano del contenido, extraordinarias similitudes.

«Yo persigo una forma» se publica en la segunda edición de Prosas Profanas, dentro de las adiciones, en un momento en que se ha producido una verdadera transformación, sustancialmente anímica y temática en la lírica dariana. El cambio se centra en la elección de un tema esencial a partir de este momento en su poética como es Calibán ${ }^{1}$, si bien no se desarrollará con amplitud hasta Cantos de vida y esperanza.

Sin embargo, «Yo persigo una forma» no incide en el arielismo, ni en el concepto de hispanismo, sino que responde y adorna con un broche perfecto el ideal parnasiano de la forma que constata Alberto Julián Pérez, con respecto a «Friso»: "pone gran cuidado en resaltar todo lo que sea valor acumulado en la imagen: la riqueza de las formas (acompañadas de la riqueza y distinción del vocabulario) la nobleza de los personajes mitológicos, la plasticidad y el carácter visual del cuadro que hace más fácil su representación y apropiación» (Pérez, 1992: 33).

No es el primer poema, sino el último, pero cierra de un modo magnífico el proceso de una poética, la de Prosas profanas, en la que sustancialmente se busca el dominio sobre la forma lírica, iniciado en el misterio. La misteriosa risa de la divina Eulalia finaliza en el enigma, que, en este caso, es el de su emblemático cisne, quien vuelve a interrogar con su blanco cuello. Un cuello que ha sufrido el proceso de depuración y transformación que liga a Rubén Darío con las vanguardias por su esquematismo tan cercano a las doctrinas del cubismo pictórico. El botón de pensamiento que busca el desarrollo espectacular en la rosa abierta, termina concentrado nuevamente en un signo de interrogación en su paso de símbolo a signo dibujado. Ni siquiera obtiene

1. En El Heraldo de Costa Rica Rubén publica «Por el lado del Norte» (1892) que es una respuesta al «bocado» centroamericano con el que se pretenden alimentar Estados Unidos. Existe la teoría de que William Walker había desarrollado en su «Destino manifiesto» al argumentar la superioridad de los países del Norte frente al Sur. 
lo más puramente externo porque, acorde con esta nueva imagen, se muestra inaccesible y casi inmaterial, mientras las formas huyen y la barca del sueño boga, como un velero por el espacio.

El abandono del momento parnasiano —clave en Prosas Profanas- se corresponde con la búsqueda de una profundidad esencial que coincide con el movimiento simbolista e inaugura el camino de la nueva poética dariana presente en Cantos, pero que desemboca en un río de corrientes hermanas de la Vanguardia.

\section{Yo soy aquel que ayer no más decía}

Escrito en serventesios endecasílabos, Gerardo Diego destacó la armonía del poema, que se debe a la «magia orquestal» por liberar al «endecasílabo español de la obediencia a la ley de no acentuación en séptima silaba, volviendo al endecasílabo italiano, dantesco» (Diego, 1967: 251):

La música es su más genuino prodigio, no es la de la métrica estrófica, sino la de la idea. La espiritual, pero manifestada por el único procedimiento que el lenguaje le proporciona, la sucesión melódica silábica (...) El ritmo yámbico de todos los pies del primer verso se contrapone al freno, casi al retroceso de los del segundo. Y, sin embargo, materialmente son casi los mismos elementos tónicos y átonos los que juegan en cada verso (id., 256)².

En él subraya Octavio Paz, también, la cualidad de ser elegía y al mismo tiempo una declaración de los cambios experimentados en su juventud (Paz, 1964: 45).

El poema lo publica Azorín por primera vez en Alma española en 1904 (7 de febrero) y como indica Olga Muñoz abría el espacio a una sección que se pensó estaría dedicada a autobiografías. El poema, en la revista, venía precedido desde la página anterior por una cita de Castelar iniciada, así mismo, por la primera persona del singular: « ¡Yo amo con exaltación á mi patria, y antes que á la libertad, antes que á la república, antes que á la federación, antes que á la democracia, pertenezco á mi idolatrada España!». Confesión de patriotismo y al mismo tiempo acentuación del hispanismo que será el tema más profuso de Cantos de Vida y esperanza ${ }^{3}$.

2. Serventesio, endecasílabo con rima $\mathrm{ABAB}$, con alternancia entre el endecasílabo heroico y el melódico en razón del peso acentual.

3. El origen de la relación con Castelar se remonta a la fundación de la Biblioteca nacional de Nicaragua en 1882. En la inauguración estaba previsto que Rubén leyera su poema «El libro», pero no lo hizo y esta lectura se trasladó después a la apertura del congreso. Las donaciones procedían desde el año 1872 de personalidades como Desiré Pector (cónsul de Nicaragua en Francia). Para la donación de los libros en castellano 


\subsection{La dedicatoria}

Desde la primera edición en volumen el poema y la sección (Alfonso García Morales) está dedicado a Rodó. Rovira y Arellano encuentran la causa de la dedicatoria a Rodó en el arielismo que se hace patente en la primera sección del poemario.

En otros ensayos he defendido que el arielismo procede tanto de Renan como de Peladan, y tiene su origen en la invasión de Alemania a Francia, de 1872, que se transforma en una propuesta simbólica centrada en los personajes de La tempestad de Shakespeare, en la que se propone a Ariel, como paradigma. Sin embargo, durante bastante tiempo, se hablará más de Calibán, su oponente, que de Ariel. En Darío el inicio del tema se data, como recuerda Jorge Eduardo Arellano, en 1893, en un temprano escrito sobre Augusto de Armas (6 de agosto de 1893), donde ya identifica nuevamente a Calibán con el materialismo ${ }^{4}$. En su «Polilogía yanqui», así mismo de 1893, dedica al tema siete textos de La Habana Literaria. De igual modo al referirse a Edgar Allan Poe «habla de un Ariel entre calibanes» (Arellano, 2014), y nuevamente en el artículo «El triunfo de Calibán», el término será aplicado a Estados Unidos. Como ya he indicado («Rubén Darío en el eje del 98», «Panamericanismo y lenguaje») es en la base del pensamiento de Peladan (1858-1918) defensa de los valores tradicionales franceses, basados en la leyenda y el arte, y posteriormente de Renan (18923-1892) ${ }^{6}$ en los que encuentra la motivación suficiente para enfrentar a los dos protagonistas de La Tempestad de Shakespeare. Renan defiende razones más espirituales que materiales en sus escritos Qu'est ce qu'une nation (La Sorbona, 1882) y en su obra teatral Caliban (1878)

el gobierno nombró una comisión de intelectuales españoles presidida por don Emilio Castelar. Es en la biblioteca donde lee la colección de la Biblioteca de Autores españoles. Rubén Darío redactó un ensayo político cultural sobre su figura.

4. El antecedente del concepto de calibanismo, según Arellano («Los raros, una lectura») se encuentra en el temprano ensayo (1893) sobre Augusto de Armas que posteriormente se incluirá en Los raros, en el que el nicaragüense señala la cita de Peladan quien se refirió a Estados Unidos como un país de Calibanes. Por su parte David Allen cita también como patrocinador del término a Groussac quien en 1897, en un artículo («Chicago, la ciudad y la exposición» sobre la World's Columbian exposition organizada en Chicago) afirmaba que el calibanismo era expresión de la belleza brutal (Jaúregui, 347).

5. Josephin Peladan, (seud. Sar) en libros como Le Vice supreme, el ocultismo aflora como fuerzas secretas que tratan de destruir la humanidad. Fundador de los rosacruces junto a Stanislas de Guaita, orden a la que perteneció el amigo de Darío E. Encausse, Papus. La religión de la belleza promueve la leyenda antigua y el ensueño, el mito y la alegoría.

6. Renan ya había indicado ante la invasión de Alsacia y Lorena que la pertenencia a una nación no estaba en la unidad de lengua o raza, o política, sino en el deseo democrático de adscribirse a una u otra nación. La Réforme intellectuelle et morale (1871), inspirado por la derrota de 1870 y la crisis de 1871.

Anales, 28 (2016), pp. 153-169 
donde proclama la necesidad de una élite que guíe el proceso político de las naciones. Pero Darío no es el único. Seguidores de la apropiación de los personajes de La Tempestad, como paradigmas de acciones sociales, encontramos en el discurso de Paul Groussac (Jáuregui, 1998: 246).

Así mismo las razones de la dedicatoria a José Enrique Rodó se podrían encontrar en otros motivos, y se remontarían a una serie de desencuentros entre ambos a raíz de la publicación de Prosas profanas. El estudio que hizo el uruguayo sobre esta obra de Darío apareció en la segunda edición como introducción pero sin la firma de Rodó, lo que Darío justificó como problema editorial, sin evitar que el autor de la crítica se molestara, como era natural. Lo cierto es que no todos los comentarios que hizo sobre Prosas profanas fueron favorables. Tal vez por las relaciones que inicialmente había mantenido con Clarín, quien, en años previos, fue uno de los detractores más acérrimos del modernismo y de Darío. Así las cosas, la dedicatoria resumía el espíritu conciliador con el que ambos modernistas coincidieron finalmente puesto que Cantos de Vida y Esperanza sí se correspondía con el espíritu de compromiso que solicitaba Rodó al poeta.

\section{El yo confesional}

Pero Rubén no habla en este poema de España, sino de él mismo y de su poética. Las relaciones con «El Reino interior» de Prosas Profanas (cierre del poemario en la primera edición) son cristalinas, en especial, por el juego de dualidades y la oscilación entre el bien y el mal, que se repite en ambos poemas. En un fin de siglo marcado por una crisis de identidad, Darío se esfuerza en explicar la dualidad como característica de la tensión lírica.

Desde el comienzo se destaca la importancia del yo confesional, hasta el punto de que Mejía Sánchez calificó al poema de biografía lírica y espiritual. Por su parte Díez de Revenga lo situaba dentro de una tendencia al autorretrato frecuente en escritores modernistas como Machado o Juan Ramón [Jiménez] (Diez de Revenga, 1997: 65), lo que se refuerza con la propia sección en la que se incluye el poema dentro de la revista, por iniciativa de Azorín, una sección «de autorretratos para presentar los valores jóvenes, pero ya consolidados del panorama literario español» que señalaran «el papel de la juventud y del arte en la sociedad moderna» (García Morales, 1994: 295).

El poema concentra y explica en sus versos el proceso mediante el cual se ha desarrollado desde la experiencia el fenómeno estético. Es una conversión de la materia lírica en el propio poeta. Como indicó José Ortega una búsqueda del otro o lo otro: «Hacer de algo un yo mismo: único medio para que deje de ser cosa» (Ortega y Gasset, 1994: 250). De este modo la materia lírica, 
la formación de una poética, se integra en una autobiografía que deviene a su vez una construcción de sí mismo desde la literatura, como demuestran los términos literarios autorreferenciales — «el verso azul y la canción profana»— que utiliza.

La referencia al tiempo del presente es una de las claves del poema. El «yo soy» del comienzo nos remite a una utilización del sujeto en el ahora que se ubica en la brecha temporal: un punto de inflexión atemporal entre el pasado y el futuro. Es una definición del yo, precisamente por la utilización de un tiempo actual, capaz de definir la esencia. La esticomitia, por su parte, es eficaz en esta función afirmativa que delimita, como una sentencia, el presente y nos ubica en un tiempo sin tiempo: la intemporalidad del pensamiento y de la confesión.

En cuanto a las posibles intertextualidades señalaba Jorge Eduardo Arellano, en su edición de Cantos de vida y esperanza las similitudes con el cuarto capítulo de Viaje del Parnaso de Cervantes: «Yo soy aquel que en la invención excede / a muchos» (Darío, 2005b:, p. 29). Y, sobre todo, como consignó Anderson Imbert, es una referencia a Víctor Hugo y sus reiterados: «Je suis celui qui» comienzo del verso con el que el poeta francés solía pasar como poeta inconfundible (Anderson Imbert, 1967: 173): «Je suis celui qui prouve à tous qu'ils ne sont rien; / Je suis toute l'aurore et je suis toute l'ombre; / Je suis celui qui sème au hasard et sans nombre» (Hugo, "Entre lions et rois, quelq'un met le holá», 2014: 3127). Y en «Ibo», de Les contemplations: «Je suis celui qui rien n'ârrete / Celui qui va / Celui dont l'âme est toujours prête / A Jehovah»

Mediante la intertextualidad del «yo soy» victorhuguesco el poeta refuerza la impronta del sujeto marcado por el ser divino del genio y al mismo tiempo intensifica mediante la cita de sus obras la autorreferencia, como recurso necesario en el propósito de iniciación del lector que asume toda la poética dariana. Esta autorreferencia reconoce el peso y la exigencia de la experiencia lírica vivida en el pasado: «el verso azul» y la «canción profan».

Frente a su torre de marfil y el parnasiasmo de Prosas, Darío expone un cambio. Era el que «ayer decía» pero cuyo cambio va a reflejar en el poema. De este modo se proyecta hacia el futuro, al tiempo que refiere su compromiso consigo mismo y con la sociedad, dominando a partir de este momento la reflexión. Frente a Prosas profanas el contenido predomina sobre la forma y la armonía, con su referencia a la analogía del símbolo, se convierte en una tendencia ahora sí constante. La forma, si bien importante, deja de ser el propósito esencial buscado por el poeta, como destaca Rovira, para abrir paso a un complejo universo simbólico donde al autor le obsesiona la comunicación de su pensamiento a través de la inaccesible ley de la analogía. 
Señala Alberto Julián Pérez que la poesía, ahora simbolista, trata de transformarse en una «esencia». «Su límite es el carácter figurativo de su imagen poética, que no puede eliminar el significado de signo y ser puramente música» (op. cit.: 116).

\subsection{Las dualidades del yo}

En el proceso de definir su poética el poema se construye sobre una clara bipolaridad, desarrollada mediante el juego de dualidades, como espejo en el que se refleja la ambivalencia de la vida humana y la obligada elección que vuelve incompatible la armonía de los opuestos. El poema es en sí mismo una afirmación de un extraordinario deseo de unidad que la experiencia niega.

Desde la filosofía E. Lledó, (1995: 187) señala la existencia de la dualidad compensatoria: «el yo es suma de consciencia y temporalidad, es sujeto de pensamiento porque piensa en el instante y desde el instante, y puede además actuar en él. Ese yo trascendental que acompaña a todos los momentos de la consciencia, sin identificarse con ella, no solo pone de manifiesto la esencial dualidad que hace posible la creación y su carácter especulativo, que permite fundar la memoria, sino también el latido mental que, acompañando al desgranarse del tiempo, es capaz de actuar desde el fondo de sí mismo como memoria», y añade, «lo histórico (el que yo fui) y lo presente (el yo ejecutivo) no se oponen» (Pozuelo Yvancos 2007: 227).

Esta dualidad surge a través de los reiterados símbolos que se oponen de dos a dos: noche/luz, ruiseñor/alondra (pero ruiseñor que se transforma en alondra) antiguo/moderno, fortaleza/ambigüedad: «en cuya noche un ruiseñor había / que era alondra de luz en la mañana»; «Muy antiguo y muy moderno, /[...]/Hugo fuerte y Verlaine ambiguo».

En su bestiario del pasado, los pájaros que le han acompañado han sido la paloma que fatalmente termina en el buche del gavilán en el poema "Ananke» de Azul, y esporádicamente el ruiseñor, cuyo canto se escucha en «La Cabeza del Rawi» o en "El reino interior» transformado en bulbules que acompañan a las aves raras como el papemor, compañeros de las niñas y las jóvenes. Un ruiseñor que se convierte en alondra, como indica Arellano (Op. Cit.: 30) con un verso «hoy no han cantado alondras la luz de la mañana», muy semejante, al utilizado por Dario en «Victor Hugo y la tumba» (1885) o «Yo fui [...] una alondra cantando en la mañana» de «Reencarnaciones» (1890). La alondra, afirma Gutiérrez Soto, es luz y color, anuncio del nuevo día, símbolo de la esperanza. 
El imaginario modernista surge con fuerza en la segunda estrofa a través de las rosas, los cisnes, las liras y las góndolas que le llevan a un ámbito rococó y dieciochesco como auspicio de la tercera estrofa, que es crucial en el poema.

A juzgar por su uso posterior serán claves esenciales de su poética los tres versos para la edición de los tres volúmenes de su antología: Muy siglo XVIII, Muy antiguo y muy moderno, Una sed de ilusiones infinita. En este sentido hay que adoptar estos tres términos como calificativos. Pero, ¿muy siglo XVIII? Fundamentalmente en Francia el siglo comienza cuando ya está casi terminando el longevo reinado del rey sol, Luis XIV de Francia, al tiempo que surge el esplendor de las cortes europeas. Sin embargo, pese a la pompa del rey Sol que sitúa a Francia en el axis del mundo civilizado será el reinado de Luis XV, el que desarrolle el famoso estilo rococó, y sitúe a la burguesía como grupo social con capacidad para sustituir a la antigua nobleza, como lo demuestra la presencia de la amante del rey, la sofisticada Madame Pompadour (una pequeña burguesa a la que el rey separa de su marido y da el nombramiento de marquesa), convertida en un objeto para completar cuando se refería a la rosa Pompadour en «Era un aire suave». Y es precisamente este reinado el último de la época antigua pues las arbitrariedades de la corte harán inviable la monarquía y el respeto a la nobleza que desemboca en la Revolución Francesa.

Así mismo es también el ámbito elegido por Verlaine, con su marquesa verlainiana, promotora de las fiestas galantes signadas por la sensualidad. Esta presencia del XVIII es lo que justifica así mismo la preferencia por Watteau frente a otros pintores simbolistas como Odilon Redon, Gustave Moreau o De Groux.

A su vez es la antigüedad del XVIII la que justifica el calificativo de «muy antiguo», mientras su «muy moderno» tiene un carácter auroral e innovador que se corresponde con la «sed de ilusiones infinita» y que se equipara con la noche del ruiseñor como tiempo pasado y un futuro auroral augurado por la alondra.

La antítesis de «muy antiguo/muy moderno» se extiende al ámbito poético en su «Hugo fuerte» $\mathrm{y}$ «Verlaine ambiguo», como también lo había calificado en el ensayo que le dedica en Los raros. Ambos configuran el paradigma de la poética que se inició en el «Azur», en su color del ensueño. Un paradigma que surge de los opuestos: fuerza frente a ambigüedad. Aunque aparentemente se encuentran en un plano de igualdad, sin embargo en Darío, como señala Marasso, casi siempre elige a Hugo, cuya lectura inicia en su juventud y cuyas referencias se extienden hasta sus últimos libros.

En esta líneas de elementos bipolares, las antítesis se personalizan y alcanzan a la subjetividad: la infancia se une al dolor y la juventud se niega («Mi juventud ¿fue juventud la mía?»): Pedro Salinas insiste en esta doble 
vertiente del sujeto poético en el que se hace presente la conciencia de caída, y con ella la melancolía que supone la imposible recuperación de la inocencia («potro sin freno se lanzó mi instinto»), o la negación avalada por la propia interrogación.

\section{La dualidad de los mitos}

\subsection{Pigmalión y Galatea}

Frente a las sensaciones, que envuelven la infancia y la juventud, el poeta se adentra en su propia transformación en mito. La estatua que esporádicamente había surgido en Prosas profanas, identificada habitualmente con el universo mítico, ya fueran Dianas o ninfas, ahora se convierte en el propio poeta, que creyó ser dueño de sí mismo: «se juzgó mármol y era carne viva». La referencia a la Venus de Milo surge por asociación, pues como tal estatua cerraba el poemario de Prosas profanas, en «Yo persigo una forma». La combinación de ambos versos, juzgarse mármol, del poema de Cantos y el «abrazo imposible de la Venus de Milo» del poema de Prosas, remite directamente a Verlaine, quien en sus Poemas saturnianos (1866), señalaba «Est-elle en marbre, ou non, la Venus de Milo?» (Arellano, 2005, 31). Marasso, por su parte, destacó

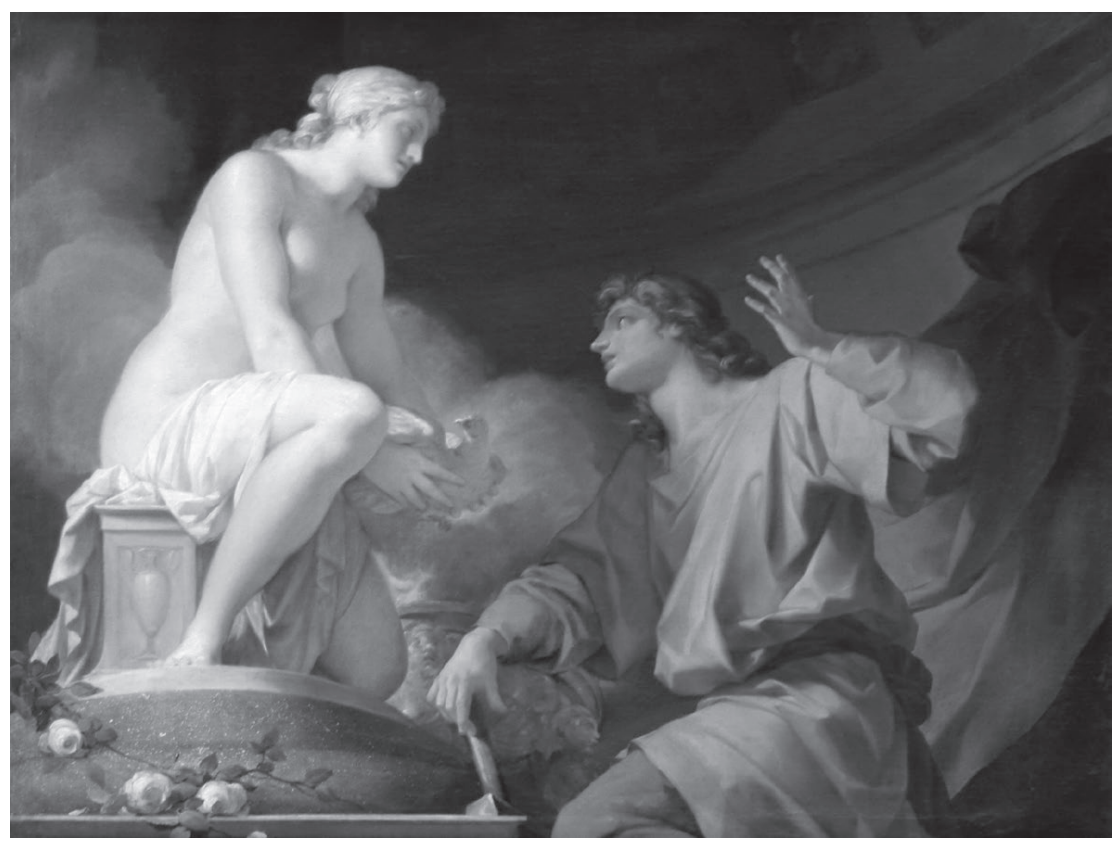

Jean-Baptiste Regnault: Pygmalion, 1786. 
el contenido iniciático de este último poema de Prosas, confirmado por el anuncio de una predicción guardada en los astros ${ }^{7}$.

La estatua remite al mito de Pigmalión de las Metamorfosis, el escultor que realiza la estatua de Galatea y se enamora de su propia obra. Símbolo de la identificación del artista con su propia obra de arte, con ecos a su vez del mito de Narciso.

El mito de Pigmalión cobra importancia como metáfora de la implicación y simbiosis del propio artista con su arte. La conexión entre obra y mito favorece la inmersión en un tiempo mítico. Un proceso de me-

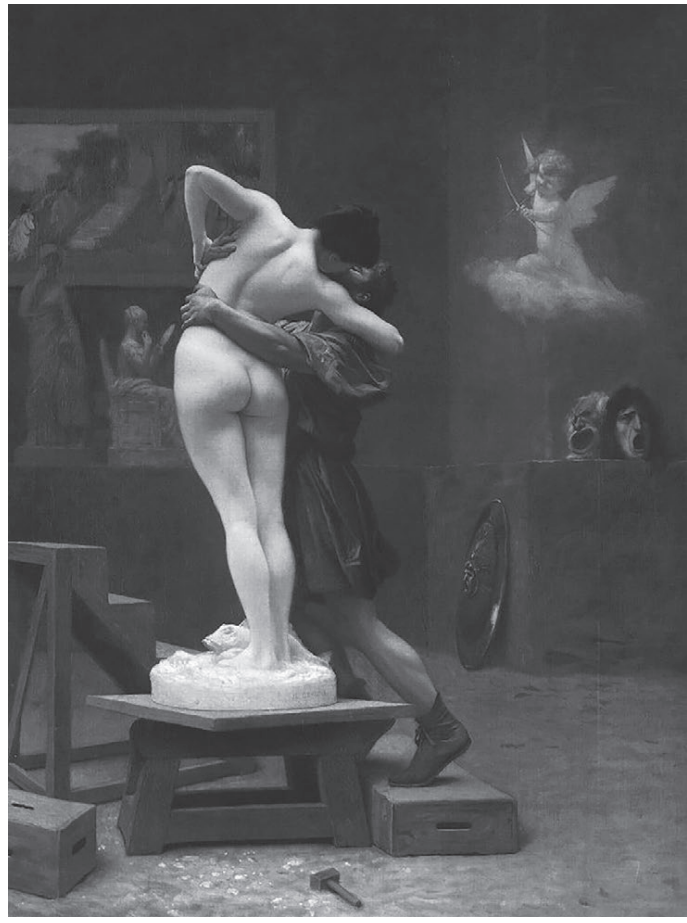

Jean-Leon Gerome: Pygmalion y Galatea, 1890. tempsicosis donde el autor $y$ su obra se intercambian favorecidos por el tiempo del ocaso donde las formas se desdibujan y todo se torna posible: «Hora de ocaso y discreto beso/hora crepuscular y de retiro». A la transformación que se va a producir contribuye la música - la dulzaina y las músicas latinas- se produce una verdadera evolución en el subfondo del universo mítico, ambientado en el mundo clásico, que logran lo imposible, el ataque a la razón y la subversión de la realidad. La estatua, signo de la belleza, obra dominada por el arte del artista, se convierte en otro personaje dual más, con patas de chivo y cuernos de sátiro, imagen de una naturaleza dominante e incontrolable (32). Una imagen impactante que roza ya las transformaciones del universo surrealista y se conecta tanto con las practicas esotéricas como con el deseo de unidad de lo diverso o aún más claramente con la narrativa fantástica.

7. Es un botón de pensamiento que auspicia la rosa. «Es la flor de Isis, la Rosa mística de la sabiduria que encierra el amor en su corazón». La Rosa mística es «El alma divina del iniciado, según refiere Schuré» (Marasso, P. 172). 
El tiempo mítico llama a su vez a un espacio donde el poeta, heredero del genio de Nietzsche se transforma en un fauno. La ensoñación y la pasión ese «ardor tan vivo"» dota de vida a la estatua, ya no bajo el mito de Pigmalión, sino en la línea de Poe de Marginalia (Marasso), donde la idea neoplatónica y divina, se acerca a través de un proceso continuado de transformaciones. La unidad del mal y del bien: Estatua: Venus de Milo y fauno, formas diversas de «Ananke», pero unidas por ser formas, por el hecho de ser y de existir. Es realmente una transformación de la belleza y la caída en el mal.

La búsqueda de la unidad es ahora la del poeta-fauno que remite a un mundo pastoril donde hace su aparición la Galatea y subraya, de Góngora, para alejarla, en este instante, del mito de Pigmalión, en equilibrio de igualdad con la marquesa Verlainiana, pero ambas opuestas porque Galatea es una mujer en la que la naturaleza se hace presente y la marquesa verlainiana, por excelencia, la Pompadour es el ejemplo del artificio y la sofisticación.

Dualidades que confirman el decadentismo que señalaba Sergio Ramírez relacionado con la fascinación de Rubén por los personajes híbridos de la mitología griega como esas criaturas feroces y carnales que «nunca son inocentes porque provienen de la culpa y cada uno encarna una historia de engaño y de violencia. La pasión es la causa de su deformidad, o de su anormalidad, y sabe sacarlos del friso de mármol insuflándoles vida y dándoles voz para expresar sus propias incertidumbres acerca del misterio de la vida y de la muerte, como en el "Coloquio de los Centauros" (Ramírez, 2016: XXV).

Entre otras dualidades: el ardor, la pasión, la sensación pura, la sinceridad, se enfrentan a la torre de marfil, símbolo de los paraísos artificiales de Baudelaire «sin comedia y sin literatura». Es «La tour d'ivoire» a la que hacía referencia el poeta francés en su texto sobre Delacroix y donde se pregunta si en ella encontraría la inspiración "qui a plus animé sa tour d’ivoire c'est-a-dire le secret?...il cherche le secret pour l'inspiration» (Baudelaire, 2014: 825) .

En su confesión Rubén equipara su corazón que absorbe el mundo, la carne y el infierno con una esponja que absorbe la sal del mar. De los tres elementos negativos para el poeta le libra la gracia de Dios que le hace elegir el Bien y el Arte, el pensamiento elevado, y la inspiración — verdadera sabiduría- que le proporciona la fuente castalia. Es la fuente la que permite que trae la armonía de la selva sagrada, tan distinta a la fuente de sangre del Baudelaire de Las flores del mal.

El eclecticismo de tintes teosóficos dariano identifica la selva sagrada con el corazón divino y la inspiración poética con la sabiduría, fuente que vence al destino. 


\subsection{Eros y Psiquis}

En la selva sagrada los opuestos se encuentran, Psiquis, símbolo de la belleza, y representación del alma humana, amada por Eros, asediada por la envidia de sus hermanas que la hicieron caer en la culpa. Frente a la espiritualidad, el sátiro fornica y el ruiseñor, Filomela, la música, se emborracha del azul del cielo.

Las dualidades y los símbolos del espíritu y el cuerpo se repiten. A través de Hipsipila y el fauno, se hacen nuevamente presentes las siete doncellas y los siete mancebos de «El reino interior», cuyas características nos dirigen a los rosacruces, sus siete mundos y sus Espíritus Virginales (omniscientes como Dios), así como las siete regiones de los mundos del deseo.

Hipsipila, la mariposa, liba en la rosa y la boca del fauno muerde un pezón. El mismo fauno que en «La epístola a la Señora de Lugones» — poema nuevamente confesional - se convierte en el propio poeta («Mas, ¿dónde está aquel templo de mármol, y la gruta / Donde mordí aquel seno dulce como una fruta?» (Darío, 1952: 838).

El dios, Pan, enamorado de la ninfa Siringa la persigue, a orillas del río, quien, para huir, se transforma en caña. Sin embargo, el dios finalmente la ata con un yugo más poderoso porque elabora con ella la siringa o flauta de Pan. Sin embargo, gracias al poder de la música, de la siringa, Pan hace brotar la Vida hasta reunirse en «la armonía del gran Todo». Una singular descripción de los conceptos ocultistas del mundo que se pueden analizar en los rosacruces. La intensa relación entre la materia, el sonido y el color se demuestra en estos ocultistas mediante la demostración de algunos efectos como ocurrió con los muros de Jericó cuando los israelitas dieron con la «nota clave» que los derrumbó. Lo mismo ocurre con el color porque «el color y el sonido están presentes a la vez, pero el sonido es el que origina el color» $\mathrm{y}$ «las formas que vemos en torno de nosotros son las figuras cristalizadas de los sonidos de las fuerzas arquetípicas que obran en los arquetipos del mundo celeste (Heindel, 2006:112):

Bosque ideal que lo real complica,

allí el cuerpo arde y vive y Psiquis vuela;

mientras abajo el sátiro fornica,

ebria de azul deslíe Filomela.

Perla de ensueño y música amorosa en la cúpula en flor del laurel verde, Hipsipila sutil liba en la rosa, y la boca del fauno el pezón muerde. Allí va el dios en celo tras la hembra, y la caña de Pan se alza del lodo; la eterna Vida sus semillas siembra, y brota la armonía del gran Todo. 


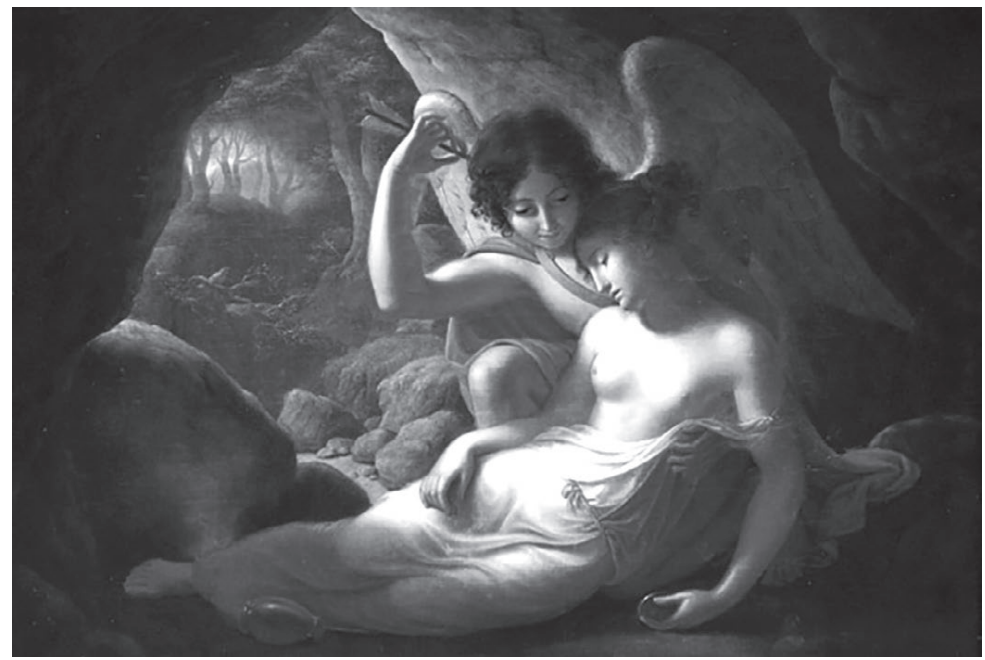

Christian Gottlieb: Eros y Psique, 1815.

El arte todo lo resume y se diviniza. En la unidad claramente ecléctica de Darío entre el mundo pagano y el cristiano, Darío exclama las palabras de Cristo: «Ego sum lux et veritas et vita», que preparan el camino para las referencias a Belén, en conexión con las teorías de los rosacruces.

El misterio de la vida se resuelve en la unidad, la armonía de los contarios, «loco de crepúsculo y de aurora», bruma y sol, toda la flauta (Pan) y toda la lira (Apolo) en sombra y luz, acorde con las teorías que se han destacado más arriba de los ocultistas.

Su confesión es una explicación a su vez de su poética. Deudor en gran medida del erotismo gnóstico, en el que el logos y el eros se unen. Porque Eros es amor erótico, pero también impulso creativo, como explica Otto Weininger en 1903 (Eros y carácter), tras su tesis doctoral sobre Eros y Psique. Al igual que para Darío, para el judío alemán el bien es el espíritu, el entendimiento y la moralidad, el mal es la sexualidad y la carne. Pero aún más en el erotismo gnóstico la contención de la sexualidad logra finalmente la longevidad y la salud, que parece repetirse en el final del poema. De igual modo que lo son las referencias a la fortaleza que reitera contenidos masónicos.

Destacaba Alfonso García Morales que el último verso es una directa alusión al Arte, pues en 1896, el poeta había afirmado que a los artistas les "guía la estrella de la Belleza», «la bandera de la peregrinación estética a los Santos lugares del arte» (1994: 308). Palabras que, efectivamente, guardan relación con el último verso pero que dejan en suspenso los anteriores. El erotismo 
gnóstico, en todo caso, se podría aplicar de igual manera, aunque tuviera como fin último no la unidad de los amantes, sino la del artista con su obra.

Es en este sentido, tal vez, en el que se pueda comprender la enigmática estrofa final que, de este modo, cobraría un significado claro, con una nueva referencia y elección por el Hugo fuerte frente al Verlaine ambiguo:

La virtud está en ser tranquilo y fuerte

Con el fuego interior todo se abrasa

Se triunfa del rencor y de la muerte,

Y hacia Belén... ¡la caravana pasa!

En todo caso, resuenan en los últimos dos versos las palabras del místico alemán Angel Silesio (1624-1677) que traduce los pensamientos fundamentales del Maestro Eckhart, citado por los rosacruces: «Aunque naciera Cristo mil veces en Belén, si en ti no nace, tu alma será perdida. Mirarás en vano la Cruz del Gólgota hasta que no se levante en ti mismo de nuevo» (Heindel, 2006: 347). Es la Navidad que debe nacer en sí mismo y que predica toda la patrística desde Orígenes a San Agustín y San Bernardo. Si bien Arellano afirma y hace coincidir la masonería y los rosacruces, parece ser que Darío camina más por los senderos del rosacrucismo de Peladan que por la masonería, al menos en esta etapa.

Para finalizar, entre otros grandes aciertos del poema el tiempo es un dato esencial. Se podría expresar como unidad de tiempos, o la anulación del tiempo. Desde el presente del «yo soy», el poeta rememora su pasado, un pasado en el que el propio poeta se transforma en mito y se ha elevado mediante este recuerdo del pretérito a la categoría de mito, en consonancia con el genio de Nietzsche. Pero a su vez, el cierre del poema es un presente con proyección de futuro, sobre todo por el tono de manifiesto, de sentencia que adquieren los cuatro últimos versos: el último, recordaba Marasso, lleva a Richepin y utiliza un término semejante al cervantino «Ladran... luego caminamos». Olvidar el mal es una promesa de vida. Belén es el comienzo de la redención, pero Belén también tiene un claro significado dentro del gnosticismo cristiano y en el rosacrucismo que hacia el final de siglo y en combinación con las doctrinas tántricas y teosóficas adquirió singular relevancia en el Buenos Aires y en el París de la época.

\section{Bibliografía citada}

ANDERSOn IMBERT, Enrique, La originalidad de Rubén Darío. Buenos Aires, Centro Editor de América Latina, 1967.

ARELlano, Jorge Eduardo, Los raros. Una lectura integral. Managua, Instituto Nicaragüense de Cultura, 1996. 
— «Rubén Darío y los Estados Unidos», Nuevo Diario, Nicaragua, diciembre 2014; <http://www.elnuevodiario.com.ni/suplementos/cultural/347847-rubendario-estados-unidos/> [visitado, 27 junio de 2015].

BAUDELAIRE, Charles, "Loeuvre et la vie d'Eugene Delacroix", en L'Art Romantique. Oeuvres completes, VI, Arvensa Éditions., 2014.

DARío, Rubén, Poesías completas, Madrid, Aguilar, 1952.

- Cantos de vida y esperanza, ed. Rocío Oviedo, Madrid, Ollero y Ramos, 2005a.

- Cantos de vida y esperanza, ed. Jorge Eduardo Arellano, Managua, 2005b.

- Cantos de vida y esperanza, ed.. José Carlos Rovira, Madrid, Alianza, 2005c.

— "Polilogia Yankee," La Habana Elegante (1893), Año 9, no.31, 6 de agosto pp. 5-7.

DIEGO, Gerardo, "Ritmo y espíritu en Rubén Darío", Cuadernos hispanoamericanos (1967), nº 212-213, pp. 247-264.

DíEZ DE REVENGA, Javier, «Vitalismo y sensibilidad de Rubén Darío. Valoración actual», Anthropos (1997), no 170-171, enero-abril.

GarCía MORALES, Alfonso, «Relectura de "Yo soy aquel", el autorretrato de Darío», en Juan Bargalló (ed.) Identidad y alteridad: aproximación al tema del doble, Sevilla, Alfar, 1994.

GuTIÉRREZ Soto, "El bestiario en la poesía de Rubén Dario", Anales de Literatura Hispanoamericana, $\mathrm{n}^{\circ} 26$ (1997), pp. 13-27.

Heindel, Max, Concepto Rosacruz del cosmos. Buenos Aires, Kier, 2006.

HugO, Victor, Oeuvres completes. Paris, Arvensa Éditions, 2014 [ebook].

JÁUREGUI, Carlos, "Calibán icono del 98. A propósito de un artículo de Rubén Darío". Revista Iberoamericana, vol. LXIV (1998), nº 184-185, julio-diciembre, pp. 441-449.

- «Canibalia: canibalismo, calibanismo, antropofagia cultural y consumo» en, Iberoamericana, 2008.

Coloma GonzAlez, Fidel,.Biblioteca Nacional de Nicaragua, ANABAD, XLII, n ${ }^{\circ}$ 3-4 (1992), pp: 301-311.

LLEDÓ, Emilio, Pequeños artículos y otras notas, ed. Mauricio Jalón, Valladolid: Consejería de Cultura y Turismo, 1994.

- Lenguaje e historia / Barcelona, Ariel, 1978.

MARAsSo, Arturo, Rubén Darío y su creación poética, Buenos Aires, Kapelusz, 1954.

MuÑoz CARRASCO, Olga, «La vida de Rubén Dario cantada por él mismo: poesía como autobiografía», Anales de Literatura Hispanoamericana, no 29 (2000), pp. 165-177.

ORTEGa y GASSET, José, "La historia como sistema", Obras Completas, VI, Madrid, Alianza, 1994.

OviEDO, Rocío, "Rubén Darío en el eje del 98: España entre la crónica y el viaje", Compás de Letras, Número Monográfico dedicado a la literatura de viajes. Madrid, n. ${ }^{\circ} 7$ (1995), diciembre, pp. 181-194 
— "Rubén Darío. Panamericanismo y lenguaje" Les ateliers du sal . Numéro 4 (2014), pp. 131-142.

PAz, Octavio, "El caracol y la sirena", Cuadrivio, México, Joaquín Mortiz, 1964.

PÉREZ, Alberto Julián, La poética de Rubén Darío: crisis post-romántica y modelos literarios modernistas. Madrid, Orígenes, 1992.

Pozuelo Yvancos, José María. “¿Enunciación lírica?”, en F. Cabo y G. Gullón (eds.) Teoría del poema: la enunciación lírica, Amsterdam-Atlanta, Rodopi, pp. 41-75.

- Desafíos de la teoría: literatura y géneros. Madrid, El otro el mismo, 2007.

RAMíREZ, Sergio, «El libertador», en Rubén Darío. Del símbolo a la realidad. Obra selecta. Madrid: Real Academia Española y Asociación de Academias de la Lengua Española, 2016; <http://www.rae.es/sites/default/files/Sergio_Ramirez._ El_Libertador.pdf> [consulta: 23 enero 2016].

Salinas, Pedro, La poesía de Rubén Darío, Buenos Aires, Losada, 1948. 